\title{
Information Literacy and Sustainable Development
}

\author{
ADEDOKUN, MARY OLUFUNKE (Ph. D) \\ Department of Adult Education and Community Development \\ Faculty of Education, Ekiti State University \\ Email: mary.adedokun@eksu.edu.ng / funkadedokun@yahoo.com
}

Tel: 08034806200

\begin{abstract}
This paper examined the issue of sustainable development in the light of information literacy. Sustainable development which has been described as the development that meets the social, economic and technological needs of the present without compromising the ability of the future populace to meet their own needs; would be difficult to attain, if Nigerians still depend only on traditional literacy of only reading, writing and numeracy. This would be grossly inadequate to achieve sustainable development in this age of highly digitalized information communication technologies. There is need for individuals to access necessary information made possible with communication technologies. Access to vital information will enable each person to have equal rights to economic resources, access to basic services which eventually will lead not only to individual's sustainable development but also that of the nation. The paper recommended that diverse strategies should be put in place to help citizens acquire information literacy and each person should acquire basic skills in accessing information through digital device, and that elibraries should be encouraged in each institution of higher learning as information literacy is highly important to every sector of the economy.
\end{abstract}

Keywords: Information Literacy, Sustainable Development, Libraries Literacy, Education.

\section{Introduction}

The ability of most developing nations to achieve the earlier stated millennium goals (MDGs)which include eradication of poverty, universal primary education, gender equality and combating diseases of various kinds; among others, led to the adoption of the 2030 agenda for the achievement of new sets of sustainable development goals by the United Nations in 2015.

The new formulated sustainable development goals include among others, ending poverty and hunger, fighting inequality, having access to clean water and sanitation, good jobs and economic growth and peace and justice among others (Global Goals 2018). Good as these new sustainable goals might be, they may become a mirage and unattainable if the citizens of any nation willing to achieve the above goals lack information literacy skills (Eyong, 2016). The implication is that diverse strategies must be employed to facilitate the acquisition of information literacy by Nigerian citizens so that sustainable development goals would become realities on the individual level as well as the national level.

Traditional literacy which embodies, the arts of reading, writing and numeracy only would, therefore, not be adequate for meeting up with the present needs and those of the future. 


\section{Education}

Education is not only a social service but relevant to transformation and it is fundamental to social and personal development. When there is access to education, there is an increase in social and political awareness, and heightened aspirations (Adedokun, 2012) which will culminate in sustainable development both at the individual, local, state and national levels.

Education, is an all encompassing tool for development as it is the foundation of peace, tolerance and a healthy and civil society and one on which the achievement of the stated sustainable development goals hang through accessibility of required knowledge and skills which will enable individuals participate fully in the achievement of sustainable development goals (UNESCO, 2012).

Education in the view of Igwe (1990) serves the purpose of inculcating in the individual the knowledge and skills required to develop individual in order not to be useful only to him/herself but to the whole society in which he finds him/herself; and not being useful to him/herself and the society for new development alone but throughout his life-time and preparing ground for generations to come.

In the perception of the old educationists such as Durkheim, education relates to the action executed by the older generation upon those who are not yet ready for social life with the objective of awakening and developing the child with physical, intellectual and moral state required of him. Perceiving education in this wise is closely related to issue of sustainable development; therefore, making it imminent that education is highly important for the realization of sustainable development.

Education has been recognized as the fundamental right of every individual by UNESCO since 1948 and due to the importance of education, significant progress has been made in the fight against illiteracy. It, therefore, behooves to the government of nations to make sure that education is made accessible to all in a bid to enhance sustainable development. Madumere (1997) stresses the importance of education when he states that education and training supply needed knowledge; hence it is an investment in human capital which aims at increasing the productive capacity of human beings.

UNESCO(2013) states that educated people are more likely to understand, support, and create solutions that ensure development of sustainable cities and communities as well as to use energy and water more efficiently and to recycle household wastes. Education, therefore, is an all encompassing tool for development as it is the foundation of peace, tolerance and a healthy and civil society. (UNESCO, 2012).

Making progress for the achievement of sustainable development goals will thus depend on the level and accessibility of education by all. Access to education by all will lead to poverty reduction, improved health and a high standard of living which will eventually culminate in environmental sustainability. To address various challenges like social inequality, economic empowerment and environmental sustainability, literacy and information literacy have vital roles to play.

Prioritizing the development of education and the eradication of illiteracy is a strong strategy for promoting development and social empowerment. Giving education to all must, therefore, be the focus of any developing nation like Nigeria. Education for sustainable development policy should thus emphasize the vitality of digital literacy.

Armstrong (2004) conceptualizes the growth of realization of a person's ability and potential through the provision of learning and education experiences and thereby submits that learning and education are necessary ingredients that can bring about development in a nation. Education is, therefore, core to sustainable development. 


\section{Literacy and information literacy}

Literacy is an important tool for development hence, UNESCO 2011 in Adedokun (2012) describes literacy as the foundation of all education and lifelong learning. It is a veritable tool for development of individuals and the society at large. Improved literacy contributes to economic growth, poverty reduction and promotion of democracy while at the same time it prevents diseases through dissemination of vital information. Literacy is a tool for individual and societal transformation. It brings additional skills in problem solving. However, literacy which used to be traditionally defined as ability to read, write and engage in numeracy has gone beyond this level at this age of technological innovation. Because literacy is profound to human and historic development, it should be taken beyond the level of traditional conception to a digitalized level.

In accordance with the stated global goals, it is expected that by 2030, all men and women, the poor and the vulnerable should be able to have equal rights to economic resources as well as basic services, ownership and control over land and other forms of property, inheritance, natural resources, financial services and microfinance. Having rights to the above would depend on the amount of access to necessary and vital information. This type of information could not be supplied only through traditional literacy hence, the need for information literacy. This view is supported by Information Federation of Library Association (IFLA) that "increase access to information and knowledge, underpinned by universal literacy is an essential pillar of sustainable development" (IFLA, 2018). To make access to vital information easy, information literacy must be encouraged through e-library in order to provide and increase digital literacy. There has been various programmes through e-library which offer instruction in basic computer skills and guidance on accessing information through the internet and to gather a wide variety of knowledge which could help in sustainability.

Information literacy would be enhanced by traditional literacy because it would be a bit difficult for someone who could neither read nor write to access information through the use of information communication technology tools. It is therefore expedient that traditional literacy could not be underestimated in the process of encouraging information literacy for sustainable development.

Every sector of the economy could benefit from accessing vital information through information communication technology tools. For example in Romania, information literacy through e-library helped farmers learn how to use the information communication technologies in libraries to access financial forms and submit such to the government through the same route and 100,000 farmers got 187 million dollars in subsidies via internet and computer services in 2011-2012. (IREX, 2013). This example shows that everybody in any nation can benefit from information literacy as long as one attains a level of literacy that will make for vital accessibility. Having access to information is not only dependent upon owning a personal computer but being trained on how to put such to use to source for necessary information that would lead to sustainable development both for now and the future. This is predicated on individuals being literate in the traditional and digital ways. This is because a person who is not lettered will find it difficult to understand the digital language let alone of being able to put to adequate use necessary communication technologies. There is, therefore, the need for training both at the rural and urban levels and the literate and semi-literate persons should be carried along in the use of information communication technologies to access correct and vital information in order to imbibe in them the values embedded in accessing information through information communication technologies.

Shafack (2016) in her study on library and information science strongly emphasized that in discussing information literacy, the library science as a discipline should not be underestimated because the library and information science drive the knowledge economy. To Shafack, the information profession is critical in the development agenda because it provides the platform on which to access necessary information that enhances the progress of human activities. She explained further that it is closely linked to information literacy which helps people to access quality information to enhance socio-economic needs thereby leading 
to healthy living and improved standard of living which ultimately brings hope for sustainable development. One of the main criteria of categorizing a country as developed is the level of the development of its information systems.

The educational development of a nation will determine the overall growth of the nation economically, socially, culturally and politically; this is why government of nations who are conversant with the importance of information strives to make accessibility to vital information a necessary and important part of its efforts at building a nation and people that are sustainable.

Emphasizing on the role of library in information literacy IFLA has as one of its objectives " to strengthen the ability of the library and information sector to advocate for equitable access to information and resilient sustainable library communities. This association is of the belief that increased access to information and knowledge underpinned by universal literacy is an essential pillar of sustainable development (IFLA, 2018). Libraries are training grounds for accessing important information at the community levels since libraries are expected to be domiciled in every community and in community schools.

Highlighting the impact of information, Shafack (2016) explained that development is about information literacy as it renders people literate in various domains of life needed for the advancement of the society; she states further that information is what is essential in building skills needed for transformation in every aspect of human life and that of the society; and that information helps in transforming human minds and that the end result is development. The above implies that relevant information from every angle and from where it is viewed is a developmental resources.

Shafack also emphasizes the roles of library (community and school libraries) in engendering information literacy by these clear facts that -

$>$ Library supports a culture of literacy and fosters critical thinking and enquiry.

$>\quad$ Through library, people can harness the power of technology and the internet to improve their lives and their community.

$>$ And that library offers access to the world's knowledge.

Advocating for information literacy therefore, library has vital roles to play.

The importance of literacy is captured by Irina Bokova, Director General of UNESCO, 2015 that

"Literacy is indispensable to raise awareness and gather necessary grassroots participation in our efforts to improve the way we care for our planet and manage its resources. This information can only happen if society's most vulnerable youth and adults acquire basic literacy skills that equip them with knowledge and confidence to improve their own lives and build more resilient communities".

The above shows the importance of literacy be it traditional literacy or digitalized literacy. People are the centre of sustainable development, thus they must be adequately sensitized and enlightened for sustainable development by reducing the level of illiteracy to the barest minimum because education is a vital tool for development.

UNESCO (2011) reveals the importance of education in reducing poverty, and improved nutrition and that with education people are less vulnerable to health risks, poverty and hunger. Information literacy and literacy will put an end to the culture of silence and self governance of the oppressed and impoverished in developing world and people will experience liberation in all spheres of life.

Robinson-Pant (2014) in her study on "Literacy and education for sustainable development and women empowerment" focused her study on how and why literacy programmes can contribute to sustainable development and processes of empowerment. She is of the opinion that literacy is related to sustainable 
development and can facilitate economic, social and environmental changes. Robinson-Pant, conceptualizes literacy as a response to increasing awareness of mental sustainability and she reports that sustainability development has not been put to practice due to lack of political will (UN, 2012a).

Dale and Newman (2005) found in their study that reconciling sustainability and development requires a complex interdisciplinary approach beyond that which is found in traditional environmental education. There is, thus, a need for an in-depth study, one which can be achieved through information communication technology as literacy has gone beyond its simple traditional meaning of being able to read, write and doing simple calculation. Literacy has gone to encapsulate problem solving skills, working in teams, communicating, negotiating and critical thinking. Based on the above, basic literacy would not be sufficient to carry through the process of sustainable development, hence, it should be coupled with digitalized literacy for proper exposure in all areas of life.

Basic literacy should therefore, be linked with knowledge about sanitation, nutrition, family planning, leadership skills, attitudinal change and adaptation to apply new technologies as well as environmental awareness. All these could be realized with modern information technology tools. Information literacy would help in realizing and achieving the three dimensions of sustainable development namely: economic growth, social equality and environmental sustainability. All these are situated within the framework of life-long learning and are based on acquisition of new knowledge, skills, technologies and values required by people. It is, therefore, important for information literacy to be included in school curriculum and its importance be entrenched in people if sustainable development is to be achieved. This is because development generally includes the enhancement of the productive capacity of the economy and the building of appropriate social relations and institutions that facilitate equitable distribution of socioeconomic benefits that accrue from the process (Olaoye, 2011).

Gboyega (2003) conceives of development as embodying all attempts to improve the condition of human existence in all ramifications - material wellbeing of all citizens, access to the good things of life, provision of personal physical security, livelihoods and expansion of life choices. All these are implied in the sustainable development goals and can be enhanced with not only basic literacy but information literacy inclusive.

Jagtah, Altom, Sin and Sherri (2015) believed that the traditional constraints of space and time will collapse with communication technologies and access to the internet. However, there is need for competence of information seekers in accessing relevant information. Jagtah etal also believe that there is a great need to bridge the gaps between tacit knowledge and explicit knowledge, between theory and practice between the competent and the incompetent. They also explain that there are various divisions such as the divide between the rich and the poor, the rural and urban residents, the male and the female, the elite and the non elite. The above represent havoc for sustainable development in all the nations of the world. Equipping stakeholders with information literacy skills would pull down these dividing walls. Information literacy is expected to teach people the art of finding solutions to emerging problems and develop in individuals the competences of evaluating information and separating useful information from the unnecessary ones.

The importance of information literacy was also emphasized when Gen. (Rtd) S. F. Rodrigues, Governor of Punjab and Chancellor of Punjabi University at a UNESCO/IFLA sponsored regional workshop on information skills for learning, advised that the contradiction between the purpose of empowering the masses with information skills and elitist approach of holding conferences, seminars and workshops should give way to reaching out to inform poor people and equip the information poor with information skills. (UNESCO/IFLA,2005). The real power of any nation is not in its money or natural resources but in human resources. Nigeria should therefore place premium on human resources and this lies solely on the value placed on knowledge and putting information to good use. 
To Jagtal (eds) education, experience, learning, proactive attitude, media and information literacy are the four pillars of progress for any commitment to nation building and peaceful co-existence. Therefore, there should not be any compromise on quality of education and integration of media and information literacy to support lifelong learning and promote the use of knowledge and information in decision making and problem solving in order to enhance sustainable development in every aspect of life..

\section{Benefits of Literacy and Information Literacy}

Some of the benefits of literacy and information literacy are stated below.

- Literacy aims at promoting social changes by empowering people (learners) with newly acquired abilities as well as through group discussion (face to face as in traditional literacy and online/internet as in information literacy) and team collaboration where ideas are shared thus promoting knowledge about human rights

- Literacy in all its forms will fight poverty and social injustice and diminish inequalities on gender and access to education by providing, education (formal/non-formal) to empower people to produce sustainable changes in their lives and communities.

- It will promote acquisition and usage of skills in reading, writing, numeracy which will help in personal and working needs

- Traditional and information literacy will empower people to fight for improved living conditions, terminate the culture of silence, teach collaboration thus resulting in sustainable social and economic changes in community.

- Information literacy has the potential of covering a wide range of fields such as health, maternal health, infant mortality, family planning, hygiene and sanitation, malaria prevention, human rights awareness, democratic governance, conflict management and resolution and violence, of all sorts.

- Literacy and information literacy will enhance livelihood skills and capacity building for income generation and community development.

- It will enhance environmental management and conservation.

Summarily, literacy (traditional and digital) empowers people for better living and for seeking solutions to challenges besetting people which are likely to make sustainable development and its goals unattainable. Information literacy makes the world a global village through which one learns new useful things everyday and it ultimately promotes individuals and societal development.

\section{Conclusion}

The researcher has through this study examined the importance of education and information literacy in sustainable development. The paper showed that though literacy in the traditional sense of the word is still relevant but that because the world is now one that is information and technological driven, information literacy has come to be important if sustainable development goals are to be achieved. The study also emphasized that e-library should encourage information literacy because the library and information science drive the knowledge economy. The study emphasized the need to bridge the gap between the information rich and the information poor and empower the information poor with information skills.

\section{Recommendations}

The following recommendations were made based in the above review.

- Education should be an important priority for government agenda for public investments especially if sustainable development goals are to be achieved. 
- Information seekers should be empowered with information research skills to search for basic needed information that would lead to sustainability.

- The library should equip its users with media and information literacy skills and government should ensure the establishment of both school and community libraries.

- Widening gap between tacit knowledge and explicit knowledge must be bridged.

- The government must provide an enabling environment for all to access education as it is then that the issue of sustainable development could be addressed.

- There should be engagement of civil society in the issue of information literacy. The National Agency for Adult and Non-Formal Education should be fully equipped for involvement in information literacy.

- Every hand should be on deck to carry out the mission of innovative and inexpensive non-formal services for adult learning in order to enable sustainable development goals especially of fighting poverty and exclusion among the undeserved communities.

\section{References}

Adedokun, M. O. (2012) The impact of Women in building a formidable community" (eds) Sotunsi, M YacolaHaliso, O Women in Africa: Contexts, Rights, Hegemonious 240 -246.

Armstrong, M (2004) Human Resources Management Practice, $9^{\text {th }}$ edition, London, kogan page.

Dale, A and Newman, L (2005) "Sustainable Development, Education and Literacy" International. Journal of Sustainability in Higher Education 6 (4) 351 - 362.

Eyong, I. U(2016) Information literacy and national development in Nigeria www.academix.ng/search/paper,html?idd-3300016544

Gboyega, A (2003) "Democracy and Development: the imperactive of local good governance" An inaugural lecture at the University of Ibadan, Ibadan, vantage publishers.

Global goals (2018) www.globalgoals.ord 5/3/18.

Igwe, S.O (1990) Professional Handbook For Teachers. Owerri: New African publishing company ltd

International Federation of Literacy Association and institutions (IFLA)(2018) How libraries contribute to sustainable development and the sustainable development goals. https:///:ifla.org/files/assets/alp/103fbradley-alp

IREX (2013) Libraries, Internet improve Farmers livelihoods, https://www.irex.org/news/librariansinternet-improve-farmers\%E2\%80\%99-livelihoods- Romania 4/3/18.

Madimere, S. C. (1997) Educational Policy and Manpower Development. Lagos: Samuel Printing Press

Media and information literacy for sustainable development goals (eds) Jagtah, S, Altom, G, Sin J.Y. and Sherri, H. C. (2015) www.mordicom.gu.se/sites/detail//milid-yearbook-2015.pdf

Olaoye, E. O. (2011) Topics in Politics of Development and Underdevelopments.Akure: B.J. Productions.

Robbison - Part A (2014) Literacy and Education for Sustainable Development and Women's Empowerment uil.unesco.org/literacy/women/literacy-and-education-sustainable-development-andwomens-empowermennt. 7/3/18.

UN (2012a): Resilient People, Resilient Partner: future worth choosing, The Report of the UN Secretary General's High Level Panel in Global Sustainability in Robinson Part, A. 2014.

UNESCO (2011) Education counts: Towards millennium development goals. New Updated Edition, Paris

UNESCO (2012) International literacy day, 8 September, 2012, Literacy and Peace, Paris.

UNESCO (2013) Education transforms lives. Paris.

UNESCO/IFLA (2005) Information skills for learning; Part II Empowering, 8 International Workshop 3-7 October, 2005, Patiala, Punjabi University. 